\title{
Components of population growth for Arctic foxes at a large Arctic goose colony: the relative contributions of adult survival and recruitment
}

\author{
Gustaf Samelius $^{\mathrm{a}, \mathrm{b}}$ \& Ray T. Alisauskas ${ }^{\mathrm{c}, \mathrm{d}}$
}

aGrimsö Wildlife Research Station, Swedish University of Agricultural Sciences, Riddarhyttan, Sweden; 'bSnow Leopard Trust, Seattle, WA, USA; 'Environment and Climate Change Canada, Prairie and Northern Wildlife Research Centre, Saskatoon, Canada; ${ }^{\mathrm{d} D e p a r t m e n t}$ of Biology, University of Saskatchewan, Saskatoon, Canada

\begin{abstract}
The abundance and distribution of animals often vary dramatically among years in Arctic environments. Such variation, in turn, is closely related to changes in food abundance and its effect on vital rates such as survival and recruitment. However, the relative importance of survival and recruitment to changes in population growth and how this varies with fluctuations in food abundance and climatic variation is poorly understood for most animals. The objective of this study was to examine how the relative importance of adult survival and recruitment to population change by Arctic foxes varies in relation to fluctuations in food abundance and climatic variation. Specifically, we used capture-recapture models to estimate how apparent adult survival and recruitment of Arctic foxes at a large Arctic goose colony varied in response to small mammal abundance, the numbers of two species of nesting geese and climate variation indexed by the Arctic Oscillation. Analyses of live capture data collected at Karrak Lake, Nunavut, Canada, from 2000 to 2015 showed that the population dynamics of Arctic foxes was driven largely by the pulsed dynamics in recruitment of foxes, whereas apparent survival of adult foxes was constant during the study. Recruitment fluctuated considerably among years and was correlated with fluctuations in small mammal abundance. Greater importance of recruitment to the population dynamics of Arctic foxes at our study site is characteristic of small and short-lived mammals.
\end{abstract}

\section{KEYWORDS}

Life history; population dynamics; recruitment; survival; Vulpes lagopus

\section{ABBREVIATIONS}

AICc: Akaike's information criterion adjusted for small sample size; AO: Arctic Oscillation; $\mathrm{CL}$ : confidence limit; QAICc: quasi-AICC
The abundance and distribution of mammals and birds often vary dramatically among years in Arctic environments (Sinclair \& Gosline 1997; Ims \& Fuglei 2005). Such variation, in turn, is closely related to the role that changes in food abundance have on affecting vital rates such as survival and recruitment (Krebs et al. 2001; Ims \& Fuglei 2005). The population dynamics of mammals is also related to longevity and life-history characteristics in that large and long-lived animals have developed strategies that favour high $(>0.8)$ and relatively constant survival of adult animals, whereas small and short-lived animals have developed strategies that favour high reproductive output (Gaillard et al. 1998; Korpimäki et al. 2004). Yet, how the relative importance of survival and recruitment varies in relation to changes in food abundance and climatic variation is poorly understood for most animals and ecosystems. Such information is increasingly important today when climate change and human alteration of the land are affecting most ecosystems worldwide (Walther et al. 2002; Ims \& Fuglei 2005).

Capture-mark-recapture analyses provide a solid framework for modelling and estimating temporal and spatial variation in demographic rates while accounting for incomplete detection of the study animals (Thompson et al. 1998; Williams et al. 2002).
Relatively recent developments in capture-recapture analyses permit joint modelling and estimation of both apparent survival and recruitment as well as the proportion of the population growth that results from survival of adults from one year to the next versus recruitment of new adults through immigration and local reproduction over the same time interval (Pradel 1996; Nichols et al. 2000). Nichols et al. (2000) have shown how the proportion of population growth rate $(\lambda)$ composed of annual apparent survival $(\phi)$, estimated retrospectively, is analogous to the elasticity of $\lambda$ to $\phi$, often projected prospectively. This parameter has been referred to as seniority, or the probability that an individual captured at time $i+1$ was present in the population at time $i$ (Pradel 1996). Similarly, the proportion of $\lambda$ composed of recruitment $(f)$ can be thought of as the prospective elasticity of $\lambda$ to $f$, and might be referred to as entry, or the proportion of the current population that is composed of new recruits (either local or immigrants) that entered the population over the previous time interval (Nichols et al. 2000). Such metrics provide important information on the relative interplay of apparent survival and recruitment to population growth, which is important for understanding population dynamics. 
Arctic foxes (Vulpes lagopus) are generalist predators and scavengers that rely heavily on small mammals (lemmings and voles) throughout most of their range, although other foods can be important in areas or years when small mammals are scarce (Audet et al. 2002). Small mammals typically fluctuate in abundance over 3-5-year periods, which has large consequences for the population dynamics of many Arctic predators including Arctic foxes (Angerbjörn et al. 1999; Samelius et al. 2011). For example, both reproductive output and abundance of Arctic foxes often vary considerably among years and in relation to fluctuations in small mammal abundance (Tannerfeldt \& Angerbjörn 1998; Angerbjörn et al. 1999; Strand et al. 2000; Samelius et al. 2011). Various measures of reproductive output by Arctic foxes generally show a direct correlation with small mammal abundance: large reproductive output when small mammals are abundant and low or no reproduction when small mammals are scarce. The numerical response of Arctic foxes, in contrast, is generally delayed by one year relative to the abundance of their primary foods (Tannerfeldt \& Angerbjörn 1998; Angerbjörn et al. 1999; Samelius et al. 2011). However, the relative importance of survival and recruitment for Arctic fox population growth is virtually unknown despite considerable knowledge about the close link between food abundance and population dynamics of Arctic foxes.

The objective of this study was to examine how the relative importance of apparent adult survival and recruitment to population change by Arctic foxes varied in relation to annual fluctuations in food abundance and climatic variation at a large Arctic goose colony. Specifically, we used capture-recapture models to estimate apparent adult survival from year $i$ to $i+1, \hat{\phi}_{i}$, and recruitment of foxes from year $i$ to $i+1, \hat{f}_{i}$. Moreover, we examined how annual variation in these vital rates was linked to the abundance of small mammals in year $i$, number of nesting geese in year $i$, and annual variation in AO between year $i$ and $i+1$. We also used the estimates of apparent adult survival and recruitment to derive the annual rate of population change, $\hat{\lambda}_{i}=\hat{\phi}_{i}+\hat{f}_{i}$.

\section{Methods and materials}

\section{Study area}

This study was conducted at Karrak Lake $\left(67^{\circ} 14^{\prime} \mathrm{N}, 100^{\circ}\right.$ $15^{\prime} \mathrm{W}$ ) in the Queen Maud Gulf Bird Sanctuary, Nunavut, Canada (Fig. 1), from 2000 to 2015. Karrak Lake is the second largest known colony of Ross's goose (Chen rossi) and lesser snow goose (Chen caerulescens caerulescens) in the world (Kerbes et al. 2014), and numbers almost doubled from about 700000 to 1300000 nesting geese during this study (Alisauskas et al. 2012; Wilson et al. 2015). Geese are present at Karrak Lake from late May to early July, after which they disperse within the bird sanctuary and only a few geese remain at or near Karrak Lake (Ryder \& Alisauskas 1995). Geese begin to migrate south in mid-September and are absent from the study area until late May the following year. Arctic fox diets at Karrak Lake are dominated by small mammals, geese and eggs (Samelius et al. 2007). Small mammals present in the area include collared lemmings (Dicrostonyx groenlandicus), brown lemmings (Lemmus sibiricus) and northern red-backed voles (Myodes rutilus). The closest community is Gjoa Haven, ca. $250 \mathrm{~km}$ to the north-east, and there was no harvest of foxes at Karrak Lake.

\section{Capture and marking of Arctic foxes}

We captured adult Arctic foxes ( $\geq 1$ year old) in May each year using box-traps (plastic and wire traps) and padded leghold-traps (Softcatch No. 1), following Samelius et al. (2003). We determined the sex of foxes by their external genitalia and marked them individually with plastic eartags (Dalton ID Systems). Foxes were captured in a $5 \times 14-\mathrm{km}$ area in the south-central part of the colony, which was constant in size and shape among years (Fig. 1). We calculated the effective size of the trapping area by adding a buffer of $2.5 \mathrm{~km}$ around the main trap sites. The size of this buffer was based on the radius of an averagesized home range of an Arctic fox at Karrak Lake (Bantle 1998) and on the observation that we commonly saw foxes in areas that were about $2-3 \mathrm{~km}$ apart in spring (unpubl. data). The size of the effective trapping area was $128 \mathrm{~km}^{2}$, of which $91 \mathrm{~km}^{2}$ was terrestrial habitat and $37 \mathrm{~km}^{2}$ was water or ice. We used ArcGIS 10.1 (Environmental Systems Research Institute, Redlands, CA) to calculate areas of water and land from a digital land-cover map produced by Didiuk \& Ferguson (2005). Arctic foxes spend most of their time travelling on land

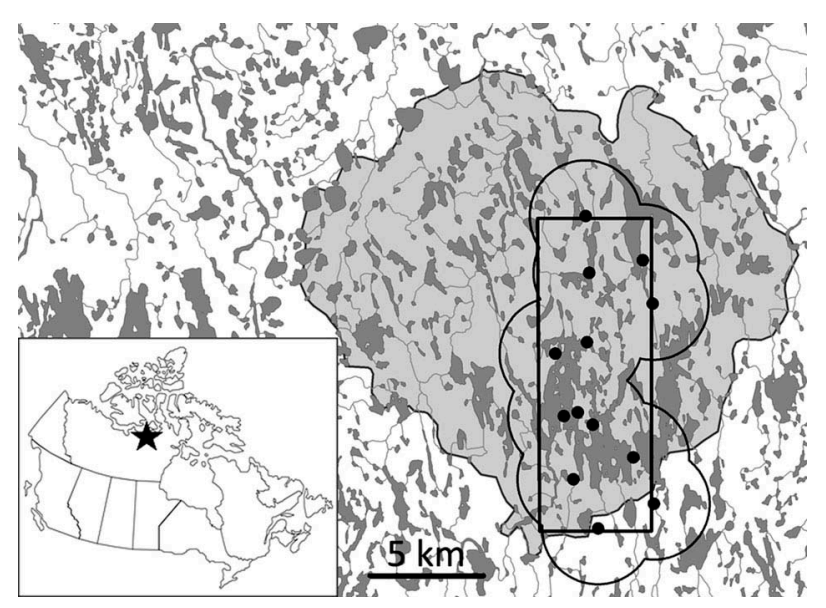

Figure 1. Location of the large goose colony at Karrak Lake in the Queen Maud Gulf Bird Sanctuary, Nunavut, Canada. The goose colony is outlined in light grey in the insert map and the study area for capturing and marking foxes is outlined by the black rectangle. The main trap sites are indicated by black dots and the effective trapping area using a $2.5-\mathrm{km}$ buffer around the main trap sites is outlined by the dark grey line. 
after icemelt in late May and early June (GS, RTA, pers. obs.), and therefore estimates of fox density are sensitive to whether only terrestrial habitat use or the use of both terrestrial habitat and water bodies is considered. Because we had difficulties capturing adult foxes in the first year of the study, we included four adult foxes captured in the second year of the study that were identified by Norén et al. (2012) as being present as adults in the study area in the first year of the study; this was inferred from DNA signatures showing that the four adults captured in the second year of the study were parents to fox pups captured in the first year of the study.

\section{Goose population size}

The goose population at Karrak Lake has been monitored annually since 1993 (Alisauskas et al. 2012; Wilson et al. 2015). In brief, the monitoring is based on sample plots distributed systematically throughout the colony that provide estimates of clutch size and the number of geese that started to nest in each year (Alisauskas et al. 2012); geese that attempted to nest included birds that constructed a nest but may not have successfully completed egg laying or hatching. Ross's and snow geese were distinguished by the size of their eggs, which allows for estimation of the abundance of each species (Alisauskas et al. 1998).

\section{Small mammals}

We monitored small mammal abundance at three permanent trap-lines established in 1994, following Shank (1993). Trap-lines were located in the goose colony and consisted of 25 trap stations with a snap-trap placed within $1 \mathrm{~m}$ of each trapstation. One trap-line was monitored during the second half of June and the other two were monitored during the second half of July. We monitored small mammal abundance for 10 consecutive nights and used number of captures per 100 trapnights for each year. We subtracted 0.5 trap-nights for each trap that was snapped without capture to correct for variation in sampling effort (Beauvais \& Buskirk 1999). Trap-lines were located in habitats that included both wet lowlands and dry uplands.

We considered three types of covariates to characterize small mammal abundance in our analyses (Fig. 2): number of lemmings/100 trap-nights ( $N$ Lemmings), number of lemmings and red-backed voles/100 trap-nights $(N$ Smallmam), and an index that characterized the lemming cycle (Lemming Cycle) as follows: $0=$ no lemmings captured in year $i ; 1=$ lemmings captured, but either preceding or following a peak in annual numbers captured; or 2 = peak numbers captured in year $i$ in relation to numbers captured in years before $(i-1)$ and after $(i+1)$.

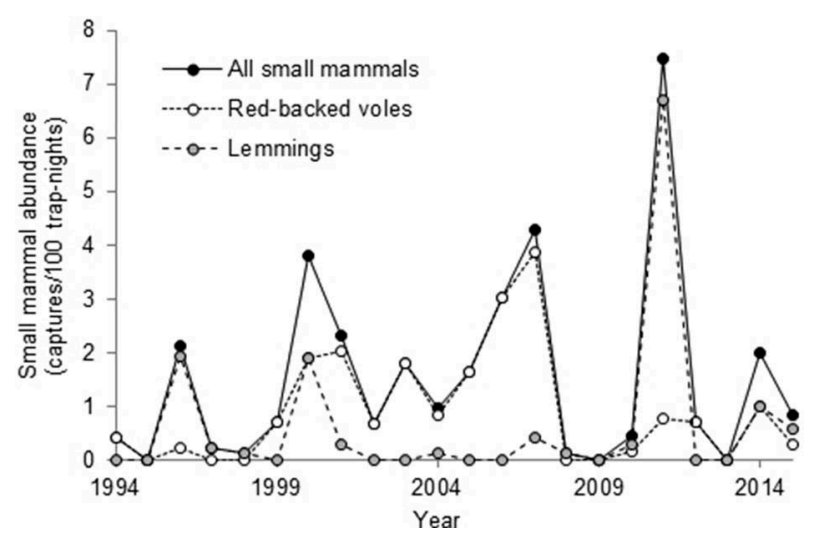

Figure 2. Small mammal abundance at the large goose colony at Karrak Lake, Nunavut, Canada, during summer in 1994-2015.

\section{Climatic variation}

We used the AO as an index of annual climatic conditions. The AO provides a measure of pressure anomalies between Arctic latitudes and areas centred between about $25^{\circ} \mathrm{N}$ and $37^{\circ} \mathrm{N}$, where positive $\mathrm{AO}$ values correspond to low surface pressure and negative $\mathrm{AO}$ values to high pressure in the Arctic (Lorenz 1951; Thompson \& Wallace 1998). We calculated annual indices as the sum of values for the AO from May in calendar year $i$ to April in year $i+1$, on the basis of data from the US National Weather Service (2015). We also considered a winter AO index (the sum of values from October in calendar year $i$ to March in $i+1)$. The two indices were highly correlated $(r=0.96)$, so we arbitrarily chose to use the winter AO index in our analyses.

\section{Modelling and estimation}

We used Pradel's (1996) model for open populations, implemented in Program Mark (White \& Burnham 1999), to estimate apparent adult survival from year $i$ to $i+1, \hat{\phi}_{i}$, and recruitment to the population from year $i$ to $i+1, \hat{f}_{i}$, where $\hat{\phi}_{i}$ was defined as the probability of remaining alive and in the study area, and $\hat{f}_{i}$ was defined as the number of new adults in year $i+1$ divided by the number of adults alive in year $i$. Our use of Pradel's model did not distinguish between mortality and permanent emigration behind removals of adult Arctic foxes from year $i$ to year $i+1$; neither did it distinguish between recruitment from immigration between years $i$ and $i+1$ and local production of young from year $i$ as contributions to the population of adults alive in year $i+1$.

We used an information-theoretic approach for optimal model selection from our candidate set of models (Burnham \& Anderson 2002). Our starting model was structured so that apparent adult survival, $\phi$, capture probability, $* * p$, and recruitment, $f$, could vary in an interactive manner between sex of adult foxes and year of study, i.e., $\quad\{\phi($ sex $*$ year $) p(\operatorname{sex} *$ year $) f(\operatorname{sex} *$ year $)\}$. Although tests for goodness of fit for Pradel's (1996) 
model do not exist in Program Mark, we performed several goodness-of-fit tests on the capture histories used in a Cormack-Jolly-Seber global model (Alisauskas \& Kellett 2014). A bootstrap goodness-of-fit test yielded $\hat{c}=1.384$ and Fletcher's $\hat{c}=0.95$, both implemented in Program Mark. However, we used an estimate of $\hat{c}=2.08$ from a median $\hat{c}$ test because it provided the most conservative approach towards adjusting variance estimates and AICc to QAICc (Burnham \& Anderson 2002). Following this adjustment, we constructed 125 models where sex and year effects were interactive $(\operatorname{sex} *$ year $), \quad$ additive $\quad($ sex + year $), \quad$ sex absent (timeyear), year absent (sex) or both sex and year effects absent (.) for each of the latent parameters, resulting in the model $\{\phi() p.() f.($ year $)\}$.

We then considered 14 additional models with inclusion of ecological covariates to recruitment and then apparent adult survival with constant capture probability. Specifically, we considered the effects of the three measures of small mammal abundance defined above $(N$ Lemmings, N Smallmam and Lemming Cycle), three measures of the number of nesting geese ( $N$ geese, $N$ Ross and $N$ Snow) and winter AO $(A O)$ on both apparent adult survival and recruitment of foxes.

We used the simple canonical estimator for abundance of Arctic foxes in each year, $i$, in our study area:

$$
\hat{N}_{i, j}=\frac{n_{i}}{\hat{p}}
$$

where $n_{i}$ is the number of foxes captured in year $i$, and $\hat{p}$ is the probability of capture over all years of the study. Our derived parameter for annual rate of population change, $\hat{\lambda}_{i}$, was estimated as $\hat{\lambda}_{i}=\hat{\phi}_{i}+\hat{f}_{i}$.

Finally, we estimated longevity $\left(\hat{l}_{i}\right.$, in years, after year $i$ ), defined as the duration that adult foxes, i.e., $\geq 1$ year old, remained alive in the study area, as:

$$
\hat{l}_{i}=\frac{1}{-\ln \left(\hat{\phi}_{i}\right)}
$$

\section{Results}

We captured 153 adult foxes, of which 42 were captured in one or more years after the initial capture. Mean residency time by adult foxes as estimated from average longevity was 1.51 years (95\% CL $=1.19$ to 1.97 years) after the first capture. However, 14 foxes had apparent residency times of at least three years. The longest apparent residency time was seven years for one male fox that was recaptured every year from 2004 to 2011, with the exception of two years during which the fox was sighted but not recaptured. There was another male fox that also had an apparent residency time of seven years when including both recaptures and resightings; its apparent residency time was six years when the analysis was limited to recaptures only. These two males were estimated to be one year old at the original capture based on tooth wear and were therefore at least eight years old when encountered the last time.

Small mammal numbers varied over 3-4-year periods that were driven largely by variation in lemming numbers (Fig. 3). Peak numbers of small mammals were captured in 1996, 2000, 2003, 2007, 2011 and 2014 , with the three largest peaks occurring in 2000 , 2007 and 2011.

We considered 139 models, from which the top models showed that neither apparent adult survival nor recruitment was different between sexes of Arctic foxes at Karrak Lake. Similarly, the top model, $\{\phi() p.() f.(N$ Smallmam $)\}$, showed that apparent survival of adult foxes was constant at $0.52(95 \% \mathrm{CL}=0.40$ to 0.63 ) during the study (Fig. 3). The top model also showed that recruitment from year $i$ to $i+1$ was related to the number of small mammals captured in year $i$ $\left(\hat{\beta}_{N \text { Smallmam }}=0.28[95 \% \mathrm{CL}=0.10\right.$ to 0.47$\left.]\right)$. Estimates of recruitment were highly variable and ranged from 0.24 (95\% CL $=0.13$ to 0.39 ) in 2009 and 2013 to 1.95 (95\% CL $=0.11$ to 3.80 ) in 2011 (Fig. 3). Analysis of deviance showed that the number of small mammals captured in year $i$ accounted for 34\% of the annual variation in fox recruitment $\left(f_{(1,13)}=6.70, p=0.022\right)$. Capture probability was constant among years at 0.48 (95\% CL $=0.31$ to 0.65 ). One competitive model, $\{\phi(N$ Ross $) p() f.(N$ Smallmam $)$, with $\Delta$ QAICc $=1.36$, suggested that apparent survival of adult foxes was positively, but only weakly, related to the number of nesting Ross's geese in year $i$ $\left(\hat{\beta}_{N \text { Ross }}=1.08[95 \% \mathrm{CL}=-1.43\right.$ to 3.60$\left.]\right)$. Analysis

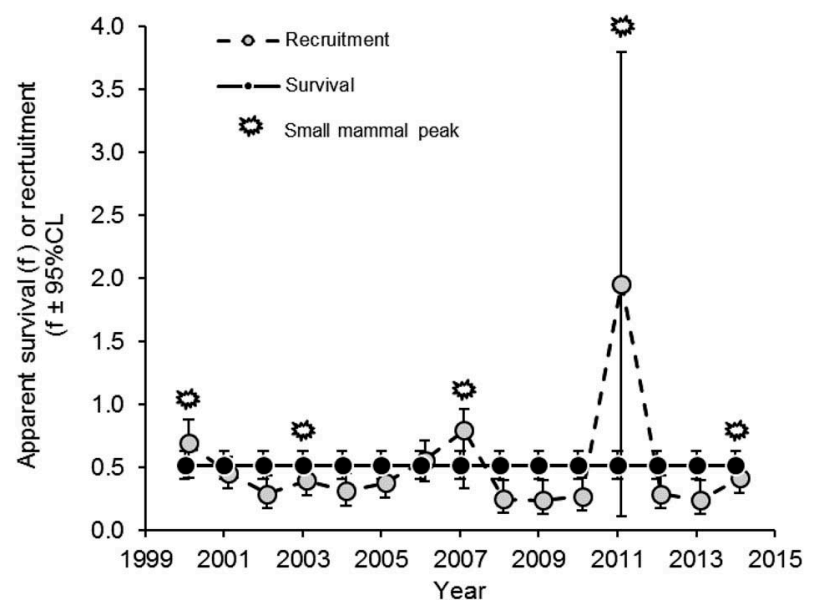

Figure 3. Annual estimates of apparent adult survival $\left(\hat{\phi}_{i} \pm 95 \% \mathrm{CL}\right)$ and recruitment $\left(\hat{f}_{i} \pm 95 \% \mathrm{CL}\right)$ by Arctic foxes at Karrak Lake in Nunavut, Canada, from 2000 to 2015, where the main peaks in small mammal abundance are indicated. Annual estimates are referenced by the starting year of the interval from year $i$ to year $i+1$, so the three main peaks in recruitment $(2000,2007$ and 2011) occurred one year following the three largest peaks in small mammal abundance. 
of deviance showed that the number of nesting Ross's geese in year $i$ accounted for only 5\% of the variation in apparent survival of adult foxes $\left(f_{(1,12)}\right.$ $=0.608, p=0.451)$. Another competing model, $\{\phi(A O) p() f.(N$ Smallmam $)$, with $\triangle$ QAICc $=1.90$, contained a non-significant effect of the AO index on apparent survival of adult foxes $\left(\hat{\beta}_{A O}=-0.02[95 \%\right.$ $\mathrm{CL}=-0.12$ to 0.08$]$ ), although the AO index accounted for only $2 \%$ of the variation in apparent survival $\left(f_{(1,12)}=0.155, p=0.701\right)$. A final competing model, $\{\phi(N$ smallmam $) p() f.(N$ Smallmam $)\}$, with $\Delta$ QAICc $=1.93$, contained a non-significant effect of small mammal abundance on apparent survival of adult foxes $\left(\hat{\beta}_{N \text { Smallmam }}=-0.05[95 \% \mathrm{CL}=-0.30\right.$ to 0.20$\left.]\right)$, although small mammal abundance accounted for only $1 \%$ of the variation in apparent survival $\left(f_{(1,12)}=0.131\right.$, $p=0.723)$. Since the three models with $\Delta$ QAICc $<2$ included only non-significant effects on apparent survival and all other models considered had $\triangle$ QAICc $>3.08$, we drew inference solely from the top model, which contained a significant effect of small mammal abundance on recruitment.

Estimates of fox abundance in our study area ranged from 14.7 (95\% CL = 9.2 to 20.2) in 2009 to 67.2 (95\% $\mathrm{CL}=42.1$ to 92.3 ) in 2002 (Fig. 4). This corresponded to a density of between 0.11 and 0.53 foxes $/ \mathrm{km}^{2}$ for the effective trapping area when considering both terrestrial habitat and water bodies, and between 0.16 and 0.74 foxes/ $\mathrm{km}^{2}$ for the same area when considering only terrestrial habitat. The fox population in our study area ranged from 15 to 42 foxes in 15 out of 16 years, whereas it exceeded 42 foxes in only one of the 16 years. There was no clear trend in the abundance of foxes over the course of the study; abundance was, instead, characterized by large variation among years.

Population growth $(\hat{\lambda})$ was positive in four years and negative in 11 years (Fig. 5). Three of the four years with $\hat{\lambda}>1$ (2000, 2007 and 2011) occurred one year following the main peaks in small mammal abundance (Fig. 5).

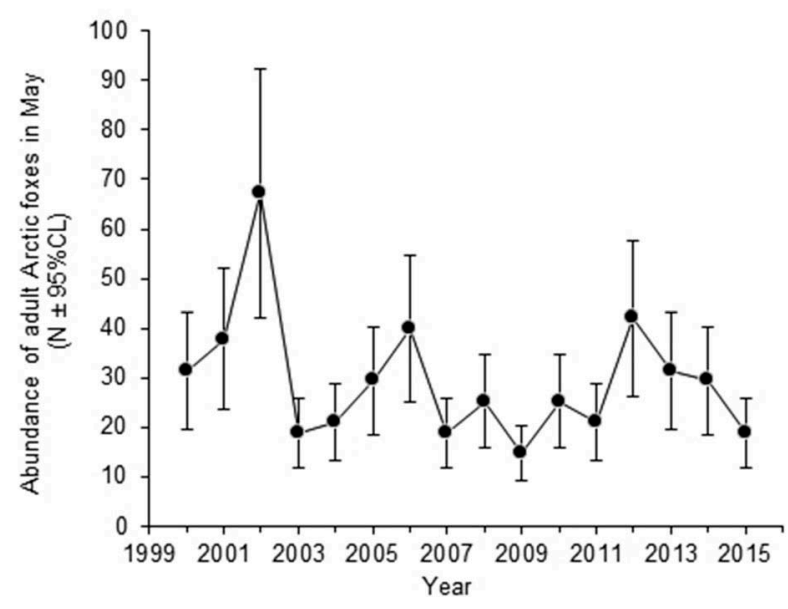

Figure 4. Abundance of adult Arctic foxes $\left(\hat{N}_{i} \pm 95 \% \mathrm{CL}\right)$ in the study area at Karrak Lake, Nunavut, Canada, during May, from 2000 to 2015 .

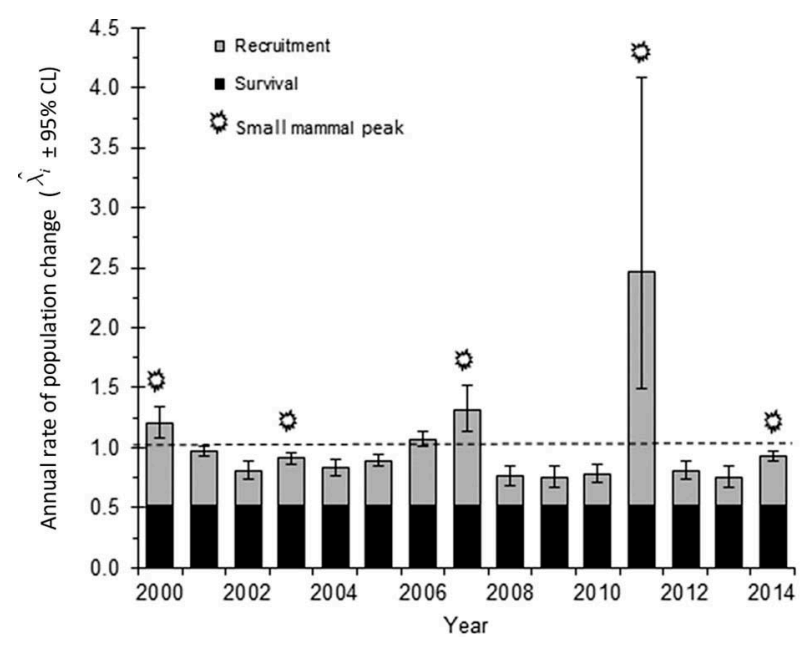

Figure 5. Annual estimates for rate of population change for Arctic foxes $\left(\hat{\lambda}_{i} \pm 95 \% \mathrm{CL}\right)$ at Karrak Lake, Nunavut, Canada, from 2000 to 2015, where the main peaks in small mammal abundance are indicated. Annual estimates are referenced by the starting year of the interval from year $i$ to year $i+1$, so three of the four years of population increase (2000, 2007 and 2011) occurred one year following the three largest peaks in small mammal abundance. The rate of population change $\left(\hat{\lambda}_{i}\right)$ was estimated as the sum of apparent adult survival $\left(\hat{\phi}_{i}\right)$ and recruitment $\left(\hat{f}_{i}\right)$. The dashed horizontal line corresponds to $\lambda=1$.

There were thus more years of population decline than of population increase despite relative population stability over the course of the study. This was largely the outcome of disproportionately large pulses in recruitment one year after the peaks in small mammal abundance coupled with a slow decline in fox numbers in the following years of relatively low small mammal numbers (i.e., a slow decline until the next small mammal peak).

\section{Discussion}

This study showed that the population dynamics of Arctic foxes at Karrak Lake was driven largely by the pulsed dynamics in recruitment of foxes, whereas apparent adult survival did not have any detectable influence on annual variation in fox abundance. The greater influence of recruitment to population dynamics of Arctic foxes at Karrak Lake is consistent with life histories characteristic of small and short-lived mammals compared to large and long-lived mammals, which tend to have relatively low reproductive output coupled with high adult survival (Gaillard et al. 1998; Korpimäki et al. 2004). Moreover, large annual variations in the recruitment and abundance of foxes fit the broader dynamics typical of Arctic environments, with large temporal changes in the abundance and distribution of animals that is typical of "boom-and-bust" systems (Sinclair \& Gosline 1997; Ims \& Fuglei 2005).

Apparent survival of adult foxes was constant during this study, with about half of the adult foxes surviving from one year to the next. This 
was somewhat lower than apparent survival of adult Arctic foxes of 0.59 in the Swedish mountains (Meijer et al. 2008). However, the foxes in the Swedish mountains were supplementarily fed as a conservation action (Meijer et al. 2008) and we suggest that apparent survival of adult foxes at Karrak Lake was likely higher than that of adult Arctic foxes in areas that are not supplementarily fed or do not have access to superabundant foods such as geese and their eggs. In fact, Arctic foxes at Karrak Lake cache 2000-3000 eggs per fox annually and they rely heavily on cached eggs in years when small mammals are scarce (Samelius 2006; Samelius et al. 2007). So, even though we did not detect a link between apparent survival and goose abundance, our finding of constant apparent survival may have been related to the nutritional subsidy provided by the geese and their eggs. More broadly, cached foods provide animals with stable and predictable foods that allow them to remain and survive in familiar areas even when other food resources become depleted (Vander Wall 1990). Individual variation among foxes in their ability to exploit and cache eggs may therefore explain some of the variation in residency times of foxes in our study: some foxes had apparent residency times of 3-7 years whereas most $(73 \%)$ foxes were captured in only one year and the average residency time for adult foxes was 1.5 years overall. The skew in apparent residency times suggests that most of the local recruitment resulted from a small portion of foxes with long residency times. The long residency times and high survival by some foxes in our study were illustrated by two foxes that survived for at least eight years, exceeding the longevity record for Arctic foxes in North America by one year (Hiruki \& Sterling 1989). However, the longest apparent longevity in our study was three years less than the longevity record for Arctic foxes on Iceland (Hersteinsson 1992), where foxes feed on foods that appear to be more stable among years than observed in North America (Hersteinsson \& Macdonald 1996). We therefore suggest that there may be a complex interplay among variation in apparent survival of adult foxes, their relative contribution to local recruitment (and thus their relative fitness), and the respective roles of goose eggs and small mammals as drivers of apparent survival and recruitment of foxes at Karrak Lake. Consequently, we hypothesize that residency times of Arctic foxes that do not have access to superabundant foods such as goose eggs are shorter than estimated in our study at Karrak Lake, where foxes had access to about 1 million nesting geese and $>1.5$ million eggs annually during this study (Alisauskas et al. 2012; Wilson et al. 2015).
Recruitment of adult foxes at Karrak Lake fluctuated considerably among years and was closely related to small mammal abundance in the previous year, which is consistent with the close correlation between small mammals and reproductive output by Arctic foxes shown by previous studies (Tannerfeldt \& Angerbjörn 1998; Angerbjörn et al. 1999; Strand et al. 2000; Samelius et al. 2011) Similarly, the population dynamics of foxes in our study was characterized by high recruitment in years following peaks in small mammal abundance, and further illustrates the pervasive link between small mammals and population dynamics of Arctic foxes in areas where they coexist (Angerbjörn et al. 1999; Samelius et al. 2008, 2011). However, since the relative contribution of adult survival and recruitment to changes in population dynamics of foxes has not been previously documented, our study also illustrates the benefit of capture-recapture models that provide unbiased estimates of different components of population growth while accounting for incomplete detection or capture of animals. Furthermore, the importance of small mammals to the recruitment and abundance of Arctic foxes at Karrak Lake shows that small mammal abundance was the key determinant of population dynamics of Arctic foxes even in areas where foxes had access to seasonally superabundant foods (see Samelius et al. 2008, 2011, for similar results).

We found that the abundance of Arctic foxes varied considerably among years and that the years of population decline were about three times as frequent as the years of population increase, despite the population showing no clear trend over the course of the study. This was largely the outcome of disproportionally large pulses in recruitment one year after the peaks in small mammal abundance followed by several years when recruitment was lower than the losses of foxes from the population. Similarly, the pulsed recruitment of foxes also suggested that cohorts contributed differently to the overall dynamics of foxes, which is consistent with the age distribution of Arctic foxes often being heavily skewed towards certain cohorts in areas where Arctic foxes and small mammals overlap (Macpherson 1969; Hiruki \& Sterling 1989). The potential of differential contribution by distinct cohorts to the overall dynamics of foxes also suggests that foxes breeding in years of small mammal peaks may have a greater impact on the genetic composition of the population. However, the average time of 3-4 years between peaks in small mammal numbers was longer than the average residency time of 1.5 years for adult foxes at Karrak Lake. Any potential effects on the genetic composition of foxes may therefore be counteracted by a few of the foxes born during years with peaks in small mammal numbers surviving to the next small mammal peak. Similarly, differences in environmental conditions at birth may result in variation in relative fitness among 
cohorts and thereby also the impact of specific cohorts on the population dynamics (Beckerman et al. 2003; Wittmer et al. 2007).

\section{Acknowledgements}

We thank J. Aitaok, J. Bantle, C. Bergman, É. Bouchard, R. de Carle, C. de Sérigny, S. Elmore, C. Hendrickson, R. Kerbes, W. Kurz, A. Lusignan, B. Malloure, K. Phipps, J. Pitt, K. Price, N. Shirley, D. Stern, J. White and N. Wiebe for excellent help and great company in the field, D. Kellett and F. Moore for logistical support, and B. Sandercock and G. White for excellent suggestions and advice that helped to improve the manuscript. Special thanks to J. Aitaok, B. Eyegetok and D. Stern for help and hospitality in Cambridge Bay. Research protocols adhered to institutional guidelines; capture and handling procedures were approved by the University of Saskatchewan Animal Care Committee (UCACS protocol number 19990029).

\section{Disclosure statement}

No potential conflict of interest was reported by the authors.

\section{Funding}

This work was supported by the California Department of Fish and Game, Canadian Wildlife Service, Delta Waterfowl Foundation, Ducks Unlimited Inc., Jennifer Robinson Memorial Scholarship, Polar Continental Shelf Project, Sweden-America Foundation, Swedish Polar Research Secretariat and University of Saskatchewan.

\section{References}

Alisauskas R.T. \& Kellett D.K. 2014. Age-specific in situ recruitment of female king eiders estimated with markrecapture. Auk 131, 129-140.

Alisauskas R.T., Leafloor J.O. \& Kellett D.K. 2012. Population status of midcontinent lesser snow geese and Ross's geese following special conservation measures. In J.O. Leafloor et al. (eds.): Evaluation of special management measures for midcontinent lesser snow geese and Ross's geese. Pp. 132-177. Washington, DC: US Fish and Wildlife Service /Ottawa: Canadian Wildlife Service.

Alisauskas R.T., Slattery S.M., Ryder J.P., Gloutney M.L., Afton A.D., Kerbes R.H. \& McLandress M.R. 1998. Discrimination of Ross's and lesser snow goose eggs. Journal of Field Ornithology 69, 647-653.

Angerbjörn A., Tannerfeldt M. \& Erlinge S. 1999. Predator-prey relationships: Arctic foxes and lemmings. Journal of Animal Ecology 68, 34-49.

Audet A.M., Robbins C.B. \& Larivière S. 2002. Alopex lagopus. Mammalian Species 713, 1-10.

Bantle J.L. 1998. Arctic fox predation on Ross's and lesser snow geese. MSc thesis, University of Saskatchewan.

Beauvais G.P. \& Buskirk S.W. 1999. Modifying estimates of sampling effort to account for sprung traps. Wildlife Society Bulletin 27, 39-43.

Beckerman A.P., Benton T.G., Lapsley C.T. \& Koesters N. 2003. Talkin' 'bout my generation: environmental variability and cohort effects. American Naturalist 162, 754-767.
Burnham K.P. \& Anderson D.R. 2002. Model selection and multimodel inference: a practical information-theoretic approach. New York: Springer.

Didiuk A.B. \& Ferguson R.S. 2005. Land cover mapping of Queen Maud Gulf Migratory Bird Sanctuary. Canadian Wildlife Service Occasional Paper 111. Ottawa: Canadian Wildlife Service.

Gaillard J.M., Festa-Bianchet M. \& Yoccoz N.G. 1998. Population dynamics of large herbivores: variable recruitment with constant adult survival. Trends in Ecology \& Evolution 13, 58-63.

Hersteinsson P. 1992. Demography of the Arctic fox (Alopex lagopus) population in Iceland. In D.R. McCullough \& R.H. Barret (eds.): Wildlife 2001: populations. Pp. 954-964. Essex: Elsevier Science.

Hersteinsson P. \& Macdonald D.W. 1996. Diet of Arctic foxes (Alopex lagopus) in Iceland. Journal of Zoology 240, 457-474.

Hiruki L.M. \& Sterling I. 1989. Population dynamics of the Arctic fox, Alopex lagopus, on Banks Island, Northwest Territories. Canadian Field-Naturalist 103, 380-387.

Ims R.A. \& Fuglei E. 2005. Trophic interaction cycles in tundra ecosystems and the impact of climate change. Bioscience 55, 311-322.

Kerbes R.H., Meeres K.M. \& Alisauskas R.T. 2014. Surveys of nesting lesser snow geese and Ross's geese in Arctic Canada, 2002-2009. Washington, DC: US Fish and Wildlife Service /Ottawa: Canadian Wildlife Service.

Korpimäki E., Brown P.R., Jacob J. \& Pech R.P. 2004. The puzzles of population cycles and outbreaks of small mammal solved? Bioscience 54, 1071-1079.

Krebs C.J., Boonstra R., Boutin S. \& Sinclair A.R.E. 2001. What drives the 10-year cycle of snowshoe hares? BioScience 51, 25-35.

Lorenz E.N. 1951. Seasonal and irregular variations of the Northern Hemisphere sea-level pressure profile. Journal of Meteorology 8, 52-59.

Macpherson A.H. 1969. The dynamics of Canadian Arctic fox populations. Canadian Wildlife Service Report Series 8. Ottawa: Department of Indian Affairs and Northern Development.

Meijer T., Norén K., Hellström P., Dalén L. \& Angerbjörn A. 2008. Estimating population parameters in a threatened Arctic fox population using molecular tracking and traditional field methods. Animal Conservation 11, 330-338.

National Weather Service 2015. Arctic Oscillation. Accessed on the internet at http://www.cpc.ncep.noaa. gov/products/precip/CWlink/daily_ao_index/monthly. ao.index.b50.current.ascii.table on 4 September 2015.

Nichols J.D., Hines J.E., Lebreton J.D. \& Pradel R. 2000. Estimation of contributions to population growth: a reverse-time capture-recapture approach. Ecology 81, $3362-3376$.

Norén K., Hersteinsson P., Samelius G., Eide N.E., Fuglei E., Elmhagen B., Dalén L., Meijer T. \& Angerbjörn A. 2012. From monogamy to complexity: arctic fox social organization in contrasting ecosystems. Canadian Journal of Zoology 90, 1102-1116.

Pradel R. 1996. Utilization of capture-mark-recapture for the study of recruitment and population growth rate. Biometrics 52, 703-709.

Ryder J.P. \& Alisauskas R.T. 1995. Ross's goose (Chen rossii). The birds of North America 162. Philadelphia: Academy of Natural Sciences /Washington D.C: American Ornithologists' Union.

Samelius G. 2006. Foraging behaviours and population dynamics of Arctic foxes. $\mathrm{PhD}$ thesis, University of Saskatchewan. 
Samelius G., Alisauskas R.T. \& Hines J.E. 2008. Productivity of lesser snow geese on Banks Island, Northwest Territories, Canada, in 1995 to 1998. Canadian Wildife Service Occasional Paper 115. Ottawa: Canadian Wildlife Service.

Samelius G., Alisauskas R.T., Hobson K.A. \& Larivière S. 2007. Prolonging the Arctic pulse: long-term exploitation of cached eggs by Arctic foxes when lemmings are scarce. Journal of Animal Ecology 76, 873-880.

Samelius G., Alisauskas R.T. \& Larivière S. 2011. Seasonal pulses of migratory prey and annual variation in small mammal abundance affect abundance and reproduction by Arctic foxes. Polar Biology 34, 1475-1484.

Samelius G., Larivière S. \& Alisauskas R.T. 2003. Immobilization of Arctic foxes with tiletamine hydrochloride and zolazepam hydrochloride (Zoletil $\left.{ }^{\circledR}\right)$. Wildlife Society Bulletin 31, 192-196.

Shank C.C. 1993. The Northwest Territories small mammal survey 1990-1992. Government Report 72. Yellowknife: Department of Renewable Resources, Government of Northwest Territories.

Sinclair A.R.E. \& Gosline J.M. 1997. Solar activity and mammal cycles in the Northern Hemisphere. The American Naturalist 149, 776-784.

Strand O., Landa A., Linnell J.D.C., Zimmermann B. \& Skogland T. 2000. Social organisation and parental behavior in the Arctic fox. Journal of Mammology 81, 223-233.
Tannerfeldt M. \& Angerbjörn A. 1998. Fluctuating resources and the evolution of litter size in the Arctic fox. Oikos 83, 545-559.

Thompson D.W.J. \& Wallace J.M. 1998. The Arctic oscillation signature in the wintertime geopotential height and temperature fields. Geophysical Research Letters 25, 1297-1300.

Thompson W.L., White G.C. \& Gowan C. 1998. Monitoring vertebrate populations. San Diego: Academic Press.

Vander Wall S.B. 1990. Food hoarding in animals. Chicago: University of Chicago Press.

Walther G.R., Post E., Convey P., Menzel A., Parmesan C., Beebee T.J.C., Fromentin J.M., Hoegh-Guldberg O. \& Bairlein F. 2002. Ecological responses to recent climate change. Nature 416, 389-395.

White G.C. \& Burnham K.P. 1999. Program MARK: survival estimation from populations of marked animals. Bird Study 46, 120-138.

Williams B.K., Nichols J.D. \& Conroy M.J. 2002. Analysis and management of animal populations. San Diego: Academic Press.

Wilson S., Alisauskas R.T. \& Kellett D.K. 2015. Factors influencing emigration of Ross's and snow geese from an Arctic breeding area. Journal of Wildlife Management 80, 117-126. Wittmer H.U., Powell R.A. \& King C.M. 2007. Understanding contributions of cohort effects to growth rates of fluctuating populations. Journal of Animal Ecology 76, 946-956. 